\title{
The strategies in passing enterprise resource planning certifications
}

\author{
Hsing-Yu, Hou
}

\begin{abstract}
The passing rate of certification is the hot topic for Taiwan Universities of Science and Technology. Therefore, the strategies for the students in computer education need to be discussed to improve successful opportunities. In this paper, action research and data mining played important roles to collect and analyze data. The instructor arranged three semesters to take experiments in Enterprise Resource Planning subjects. Also E-Learning platform was set up to provide the other practice way. From the first to the second semester, the researcher found that motivation, hard work in the learning process and review were key secrets for the students to pass the certifications. So that attitude was the basis, more practice and truly understanding were two important skills to improve the certification performance. In the third semester, there were two rules in passing the ERP exam successfully. One was that if spending time in E-Materials were high, the result was passing. The other was that if spending time in E-Materials were normal and gender was female, the output was passing. Therefore, the aided tool for students was important to review thoroughly and the performance could also be improved. Besides, the experience sharing would also contribute to the computer science education.
\end{abstract}

Index Terms-Action research, data mining, enterprise resource planning certification

\section{INTRODUCTION}

Enterprise Resource Planning developed in 1991 by Gartner Group Inc. and it depended on computers to communicate with all roles in supply chain, such as manufacturers, distributers, warehouse managers, and customers,. etc... Enterprise system, or ERP is a type of software that models and automates many business processes such as sales order fulfillment, production scheduling and integrate cross-functional information to accomplish objectives (Laudon and Laudon, 2001). ERP has become a backbone system in business nowadays. It uses new information technology, combines business processes, and integrates information across functional departments.

Relying on E-tables, the manager could check all the workflow report and make decisions quickly. The department workers could also adjust the data just in time. It combined management and functional cooperation efficiently. There were Distribution and Sales models, Production and Manufacturing models and Finance models in ERP information systems. In computer science education, certification passing rate was hot topic for Taiwan Universities of Science and Technology. If the students passed the computer certification, the enterprises would approve more than normal registrants after graduation and interview. Therefore, the strategies for the students in ERP certifications need to be discussed to improve successful opportunities.

Action research provides teachers with a valuable opportunity to get involved in research relevant to the social context of the classroom and the teaching institution, and focuses directly on important issues and concerns in daily teaching practices (Burns, 1999). Besides, action research can inspire teachers to become adventuresome and critical in their thinking, develop rationales and theories for their practice, and give reasonable justification for their claims to professional knowledge (McNiff, 1997).

Sun et al. (2008) proposed a useful approach based on data mining techniques to group students and develop an interaction monitoring system from learning portfolios to aid instructors in the facilitation of interactive communication. Hamdi et al. (2007) tried to develop an information customization system using a multi-agent approach combination with a number of aspects from the domains of machine learning, user modeling, and web mining. Chen et al. (2007) used association rule to mine the learner profile for a web-based learning diagnosis, and discovered common learning misconceptions of learners.

In the subject of Enterprise Resource Planning, the instructor arranged certification exams for the students before graduate in order to enter vocation areas successfully and practically.

How to pass the test and improve the learning performance are important educational topics in this action research. And data mining can find out successful rules for the instructor to educate the learners. The strategies for students to reflect true results can let the teacher to adjust training methods in the next semester. Therefore, this paper would contribute to successful certification learning factors and computer educational experience sharing.

\section{METHODLOGY}

\section{Definition of Action Research}

Action research has been defined variously since it was known to the world. Burns (1994) proposed that action research was to apply fact finding to problem solving in a practical social context in order to improve the quality of action inside it. It involves the cooperation and collaboration of researchers, 
practitioners and laymen. Wallace (1998) suggested that action research should be conducted by systematically collecting data on everyday practices and analyzing the data with a view to coming to some decisions about future practices.

\section{Processes of Doing Action Research}

Burns (1999) proposed, based on the collaborative action research experiences of language teachers in the Australian context that the action research process involves the following phases:

1. Exploring: It means to identify and agree on a general issue or idea of interest and then do some reading of recent books or articles to obtain ideas for research.

2. Identifying: It involves a fact finding process that enables the researchers to clarify their ideas about the focus area and prepare for more systematic investigation.

3. Planning: It means to develop a viable action plan for data collection, and consider and select a range of adequate research methods.

4. Collecting data: It means to develop the procedures selected for data collection and put them into action.

5. Analyzing/ reflecting: Close analysis of data often stimulates reflection; at the phase, the data are analyzed and interpreted systematically according to agreed criteria.

6. Hypothesizing/ speculating: Researchers have to propose predictions or a hypothesis concerning what is likely to occur, based on the data collected to this point, their analysis and the reflections arisen from the analysis.

7. Intervening: It involves changing classroom practices or approaches in response to the previous hypotheses, and several further deliberate experimenting with varied or unusual teaching methods or testing out evolving predictions or hunches by more formal means.

8. Observing: It means to observe the results of the intervention and reflect on its effectiveness. This involves new teaching activities and strategies and further data collection.

9. Reporting: It means to reveal the strategies or activities, data collection and results of the research process.

10. Writing: To ensure that the research can be disseminated to other researchers or teachers, the research questions, the process of the research, the strategies developed, and the analyses and results are drawn together in a report or article.

11. Presenting: It means to give more formal presentation of the research.

In Taiwan, Tsai (2000) proposed the major process of educational action research, which includes (a) stating the concerned problem, (b) planning the action for problem solving, (c) looking for possible co-researchers, (d) taking action, (e) evaluating the action and feeding back, and (f) presenting the report of the research.

\section{Data Mining}

Data Mining is a very important research subject in the academic and industrial areas nowadays. Michael and Gordon (1997) state that data mining can be used to explore and analyze huge amounts of data in automatic or semiautomatic ways to search for meaningful patterns and rules. They classified the data mining algorithms as the following categories. 1) Association Rules. 2) Classification. 3) Clustering. 4). Estimation.

\section{Decision trees}

Quinlan (1993, 1996) pointed out that a decision tree was a popular classification and predictive tool in artificial intelligence. The method uses tree graphics as the basis and is one of the easiest methods to generalize learning. Quinlan proposed ID3 decision tree algorithms first and then presented C4.5 to improve ID3. The ID3 algorithm applied Shannon's information theory (1949) and transformed the probability to information amount called Entropy. It then used information gain as the basis for selecting categories. Information gain $\mathrm{G}$ ( A $\mathrm{i}$ ) is the difference between all possible Entropy $\mathrm{E}(\mathrm{C})$ and Entropy $E\left(A_{i}\right)$ of a possible category $A_{i}$.

$$
G\left(A_{i}\right)=\mathrm{E}(\mathrm{C})-\mathrm{E}\left(\mathrm{A}_{i}\right)
$$

The gain ratio can be expressed as

$$
\text { Gain_Ratio }=\frac{\mathrm{G}\left(\mathrm{A}_{\mathrm{i}}\right)}{\mathrm{E}\left(\mathrm{A}_{\mathrm{i}}\right)}
$$

If an object set $\mathrm{C}$ has $\mathrm{j}$ categories, then the Entropy of the object set is

$$
E(C)=-\sum_{j} P_{j} * \log _{2} P_{j}
$$

$P_{j}=$ (total object number belong to j)/ (total object number in C)

If we select a category $\mathrm{A}_{i}$ as the decision tree leaf node, the Entropy of the sub decision tree $\mathrm{E}\left(\mathrm{A}_{i}\right)$ is $E\left(A_{i}\right)=-\sum_{k}\left(N_{k} / N\right) * E\left(C_{k}\right)$

Where $C_{k}$ is the subclass of the object set $\mathrm{C}$ that belongs to $A_{i}$ category, $E\left(C_{k}\right)$ is the Entropy of $C_{k}, N_{k}$ is the element number of subset $\mathrm{C}_{\mathrm{k}}$, $\mathrm{N}$ is the total number of objects set $\mathrm{C}$. The smaller Entropy stands for the focused information, so we should select the larger expected information gain as the first classified category.

\section{STEPS IN TAKING ERP EXPERIMENTS}

The functions of ERP are diverse and complex. No single person can control an entire ERP system. Various groups of ERP professionals need to collaborate with each other to fulfill the jobs. According to the ERP professional classification of CERPS (Chinese Enterprise Resource Planning Society), there are four groups of ERP professional including ERP consultant, ERP planner, ERP system engineer, and ERP end-user as shown in figure 1. 


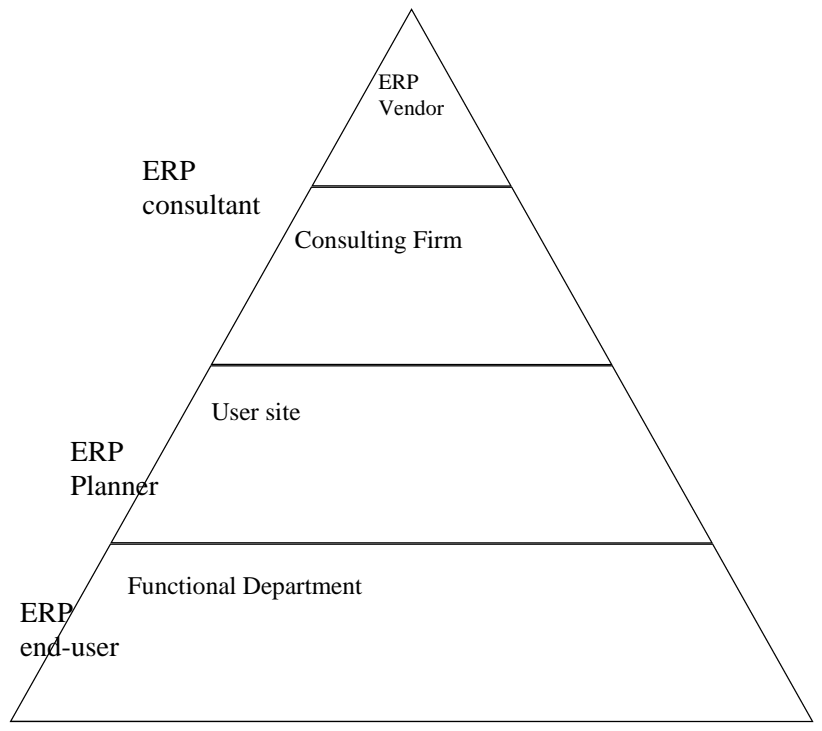

Fig. 1 Architecture of ERP professional requirement

ERP consultants in ERP vendors and consulting firms provide consulting survives such as implementation and technical support; ERP planners in user site participate and lead the implementation project, design and reengineer business processes, or analyze and design information system architecture; ERP system engineer in ERP vendor, consulting firm, and user site develop and customize ERP system, design and administrate database, or maintain network; ERP end-users in functional departments operate the functions provided by ERP system.

In this paper, how to improve the passing rate of the senior students before they graduate in order to improve their competitive ability was the importance. The researcher arranged teaching assistants (TA) to design certification training actions together. It included training periods, materials, participants, evaluation and an E-Learning aided platform to observe and collect data in the end.

\section{Period}

The instructor arranged 54 weeks during two semesters from 2010 Sep. to 2012 Jan. to teach Enterprise Resource Planning subjects. Then take the action research and do data mining.

\section{Teaching Materials}

The teaching contents included theories, PC operation and preview samples test practice. One semester of training was distribution and sales models (DS), the second semester paid emphasis on production and manufacturing models (PM) and the third semester was basic concept of IT in Data Systems Workflow ERPII. The DS chapters included sales, purchased and inventory management in the business information system. Bill of Materials, Lot Requirement Planning, Manufacturing Order and Shop Flow Control were main four parts in PM models. Basic concept of IT combined DS and PM interface introduction.

\section{Participants}

Totally 118 frequencies joined the ERP certification exams during three semesters. They were all senior college students at Transworld University and preparing for entering vocational areas.

\section{Web Records}

The input variables were class, gender, care, assignment, and E-Learning time. In the other hand, the output variable was passing or failure. Class was coded A or B. Gender was coded male or female. Care was coded high, normal or low. Assignment was coded good, normal or poor. E-learning time was coded high, normal and low.

\section{Evaluation}

The ERP Association helped the instructor to evaluate the degree of the subject in the end of three semesters. The participants had two hours to finish the certificate exams with a total of 100 items on each test to select the best answer from each four selections. 70 points meant a passing grade. The ERP exams combined comprehension, memorization and practice abilities. After the evaluation, the teacher could get the scores of all participants in this certification. Then, quality and quantity scores would be analyzed in this action research.

\section{E-Learning}

Besides training in class, the instructor wanted to provide E-Learning platform for the students to prepare sufficiently for the certification. Therefore, TA recorded Workflow ERP II operation process, then used Course Master Software to organize the contents and uploaded the Materials to Transworld University information platform. These software and surface were as bellowed:

\section{1). Recording Software---PowerCam5}

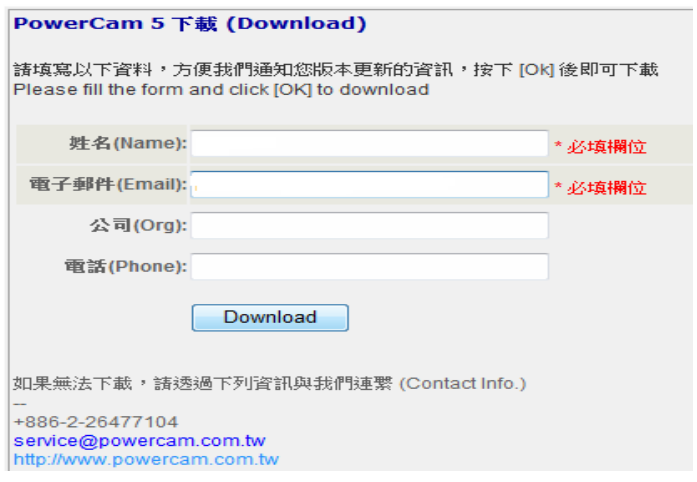

Fig. 2 PowerCam5 Download

\section{2). Recording Workflow ERPII Operation Surface}




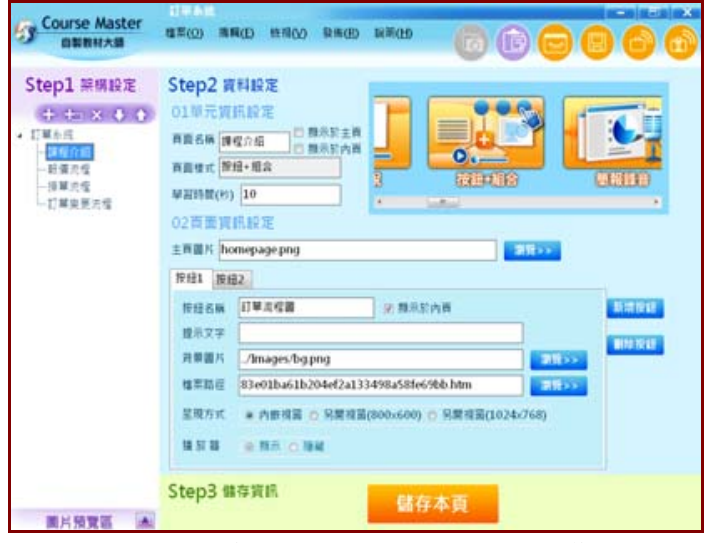

Fig.3. PowerCam5 Recording

3). Edit contents in Course Master

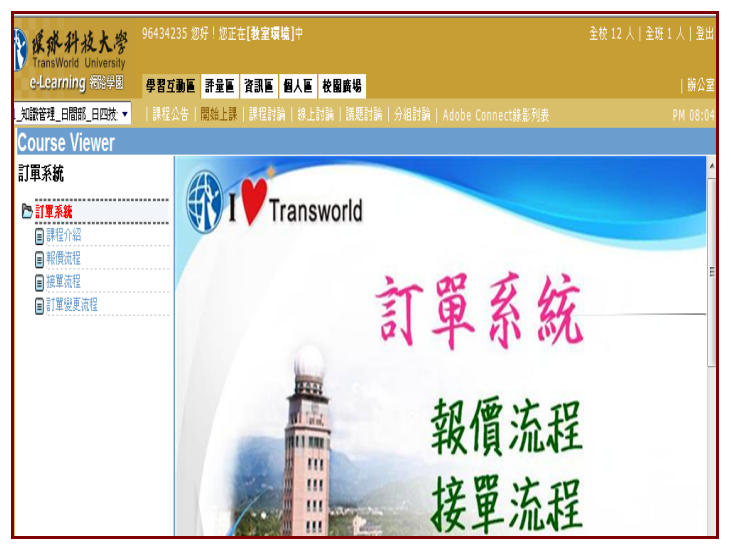

Fig.4. Course Master

\section{4). TWU E-Learning Platform}

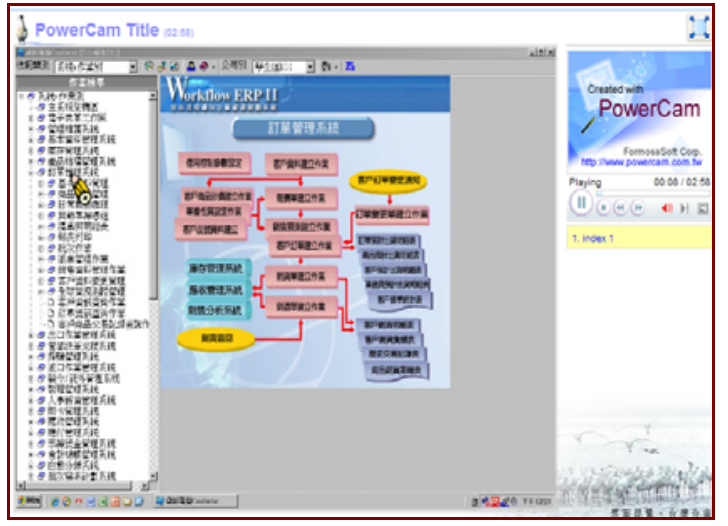

Fig.5. E-Materials

5). E-Learning Previous Samples Test

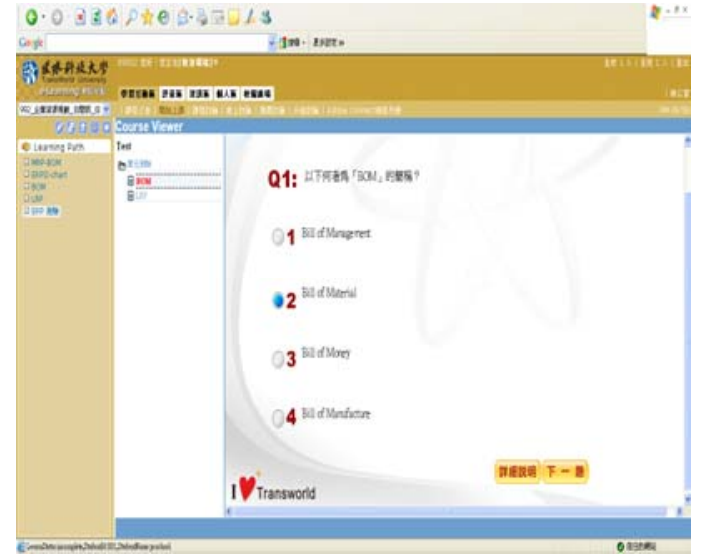

Fig.6. E-Test

\section{RESULTS}

The competitive ability to enter vocational areas was very cruel for the classmates. If we added one more certification, the accepted opportunity in enterprises would be raised. Therefore, computer education in ERP was a practical subject for the students. Passing the certification could let the students more confident than others.

After ERP tests on Jan 3, May 18 in 2011 and Jan 04 in 2012. The action research found some key points from the data.

\section{Successful Factors}

\section{Optional Course Learners}

Motivation was very important during these two tests. Because there were two ERP classes at the same time in TWU, the other class instructor didn't ask for the students to pass the computer certification. Those who changed the original class and decide to pass the certification had 0.6 passing rate.

2. Low Income Learners

Three low income students $100 \%$ all passed the exam. They appreciated the opportunities to be competitive in the future.

3. Experienced Examinees

70 percent of students who had joined the two models exams had improved scores. They wanted more agreement through passing the certifications.

4. Hard Working Learners

The two students that passed both DS and OM certification exams studied hard and posed good learning manners in class and in E-Learning records.

\section{Failure factors}

\section{Poor Attendance Rate}

Two cases who volunteered to join the ERP exam didn't pass the certification because of depending on self-learning. 
The scores below 60 affected the low participated frequencies in class. The lower learning motivation, the worse scores presented.

\section{Disrupted Language Comprehension}

Two of the foreign education students couldn't understand the meaning of the Chinese descriptions directly. It may suggest that the certification association needs to design more language forms for the students in the future.

\section{Not Overall Reading}

Two of the higher scores students in the mid-term test failed the ERP exam. They seemed only read the sample questions from previous exams and ignored the detail contents from books, especially the basic concept chapter. Because the instructor taught the computer operation more, the basic parts were needed to read by themselves in private. If they were lazy or impatient to learn independently, the results proved that something was lost.

\section{Negative}

The aggregative attitude to join the exam was very important. Before deadline the students who were late to register their name on line, the performance was poor. Maybe something bothered the student so that he or she couldn't present the usual level.

\section{Decision three rules}

The researcher found that hard working learners with E-Learning could get higher scores. There were two rules in passing the ERP exam successfully.

One was that if spending time in E-Materials were high, the result was passing.

The other was that if spending time in E-Materials were normal and gender was female, the output was passing.

Therefore, the aided tool for students was important to review thoroughly and the performance could also be improved.

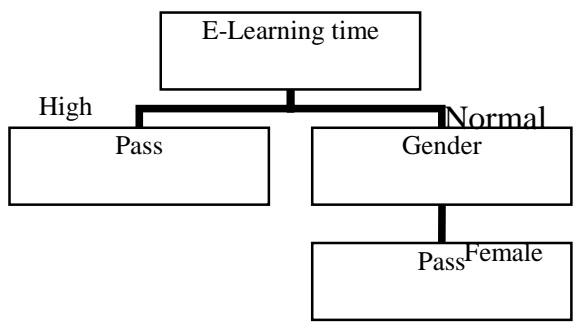

Fig.7. Decision three rules

\section{DISCUSSION}

About the operation recording in E-Learning, repeated practice trained the participants to better memorize contents.
The passing students wrote down their success and secret clues about E-Learning platform.

1. Link key points between books and E-Learning previous samples tests.

ERP workflow was step by step. The students linked the concept between books and E-Learning previous samples tests. They could underline the key points and remind themselves the operation process of all the models any time and anywhere.

2. Delete the strange words and phrases.

The operation and attention in class was limited. If we forgot the steps, E-Learning helped the recalling process. Because the instructor on-line directed the system process for us, more and more practice allowed us to memorize key words. If we prepared sufficiently, the delete way could help us find the last answer.

\section{CONCLUSIONS}

ERP curriculum may be implemented to educate and train students to become ERP professionals, perform an experimental to exam students' performance, self-efficacy, and satisfaction with the instructional design and curriculum design (Noguear, et al., 2004). Computer Education allows the ERP subject to be taught more practically and E-learning supported pushing certification successfully. In the results the researcher found that hard work in the learning process with E-Learning for the students can pass the ERP certification. It proved that E-learning played a plus role after reality computer operation in class. The experience sharing in this action research would also contribute to the computer science education in the future.

\section{REFERENCES}

[1]. A. Burns, Collaborative action research for English language teachers, 1999

[2]. C. E. Shannon, and W. Weaver, Mathematical Theory of Communication, University of Illinois Press, IL, 1949.

[3]. C. M. Chen, Y. L. Hsieh, S. H. Hsu, "Mining learner profile utilizing association rule for web-based learning diagnosis" Expert Systems With Applications Volume: 33, Issue: 1, July, 2007, pp. 6-22.

[4]. J. H. Noguear, and E. F. Watson, "Effectiveness of using an enterprise system to teach process-centered concepts in business education," Journal of Enterprise Information Management, Vol. 17, No. 1, 2004, pp. 56-74.

[5]. J. McNiff, Action research: Principles and practice. London: Routledge, 1997.

[6]. J. R. Quinlan, C4.5: Programs for Machine Learning. San Mateo, California: Morgan Kaufmann, 1993.

[7]. J. R. Quinlan, Induction of Decision Trees, Machine Learning,1, 1996, pp.81-106.

[8]. J.A Michael, and S. L. Gordon, data mining techniques: for marketing, sales, and customer support. New York: John Wiley and Sons, 1997.

[9]. K. C. Laudon, and J. P. Laudon, Essentials of management Information Systems: Organization and Technology in the Networked Enterprise Fourth Edition, New Jersey: Prentice Hall,2001.

[10]. M. J. Wallace, Action Research for language teachers. Cambridge, U.K.: Cambridge University Press,1998.

[11]. M. S. Hamdi, "MASACAD: A multi-agent approach to information customization for the purpose of academic advising of students" Applied Soft Computing Journal Volume: 7, Issue: 3, June, 2007, pp. 746-771.

[12]. P. C. Sun, H. K. Cheng, T. C. Lin, F. S. Wang, "A design to promote group learning in e-learning: Experiences from the field” Computers \& Education Volume: 50, Issue: 3, April, 2008, pp. 661-677.

[13]. Q. T. Tsai, Educational action research,. Taipei,Taiwan: Wunan ,2000 
[14]. R. B. Burns, Introduction to research methods,1994, Melbourne: Longman.

\section{Author}

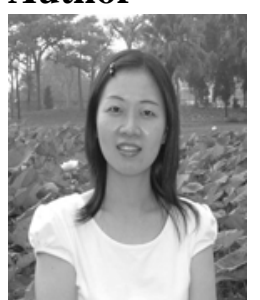

Hsing-Yu Hou is a Ph.D at the Department of Industrial Engineering and Management, National Yunlin University of Science and Technology in Taiwan. She is also an assistant professor at the department of Business Administration, Transworld University. Hou's research interests include E-Learning, ergonomics and management information systems. She has computer licenses such as advanced software application certification, $\mathrm{IC}^{3}$.international certifications, and Enterprise Resource Planning application certifications. 